\title{
Birth weight and head circumference standards for English twins
}

\author{
J M H Buckler, Martine Green
}

\begin{abstract}
This study was undertaken to provide reliable up to date information on birth weights and occipitofrontal head circumference measurements in relation to gestational age for English newborn twins. Records from 36 maternity units in England, mainly from 1988-92, have provided data on birth weights for over 19000 newborn twins with gestational ages ranging from 23 to 41 weeks, and on head circumference measurements for over 5300 twins ranging from 28 weeks to 40 weeks' gestation. Centile charts have been produced for boy and girl twins showing the distribution of these values against gestational age.

The findings confirm the greater weights of boys compared with girls throughout, increasing from a mean of about $50 \mathrm{~g}$ at early stages to $100 \mathrm{~g}$ later, in a similar way to that reported for singletons. Twins were lighter than comparable singletons by about $100 \mathrm{~g}$ at 24 weeks, increasing progressively to $4-500 \mathrm{~g}$ at 38 weeks' gestation. In contrast, differences in occipitofrontal head circumferences between singletons and twins were only evident with gestations longer than 35 weeks - and from 37 weeks' gestation onwards the mean head circumference of singletons exceeded that of twins by about $5 \mathrm{~mm}$.

It is recommended that in evaluating the significance of the birth weight of a twin in relation to gestation, twin standards such as the ones presented here should be used rather than those relating to singletons.
\end{abstract}

(Arch Dis Child 1994; 71: 516-521)

It is well known that birth weights of individual twins are less than those of comparable singletons, not only because they are born at shorter gestation but also because they are lighter for equivalent periods of gestation. Despite awareness of this fact, there are few publications with sufficiently large' numbers of twins covering a wide range of gestational age that have documented it. Reference is usually made to singleton standards for birth weight at different gestational periods, with an arbitrary ill defined correction for the fact that the babies are twins. More precise data are needed to document what may be considered the 'normal' range for twin birth weights. These data would have implications with regard to expected subsequent growth through childhood to adulthood. As over $2 \%$ of the population are twins, knowledge about them is of considerable significance. This paper reports information received on weights and head circumference measurements of twins from 36 participating centres in England, mainly in the five years from 1988-92, and from these, centile charts have been produced.

\section{Subjects and methods}

Preliminary contacts with many neonatal and obstetric units in England have resulted in a high positive response rate of willingness to collaborate in this study. Scottish centres were not included because of a recent large scale national study on all births, reference to which is made extensively in this report. ${ }^{1}$ The data have been provided by 36 English centres, and these are listed with the acknowledgments. Information on 9611 boy and 9477 girl live newborn twin babies has been obtained, with gestational periods ranging from 23-42 weeks. Most centres provided data for the five years 1988-92, but some with easily accessible records extended these to longer periods.

For most of the twins, information on birth order has been obtained, but not zygosity and, for many, ethnic origin, although at this stage no analysis of the latter has been undertaken. The data from a few referral centres providing intensive care facilities showed a predominance of very small preterm infants, which may slightly increase their representation in the overall numbers.

In addition to birth weights on all babies, occipitofrontal head circumference measurements were provided on over a quarter of the infants, but the data presented here include the 2597 boys and 2720 girls with gestational periods between 28 and 40 weeks because outside this range the numbers were too small. No information on birth lengths was requested because it would seldom have been available and the reliability would have been questionable.

\section{GESTATIONAL AGE}

The data provided from the centres have been accepted without modification and therefore may be subject to minor variability in $\unrhd$ interpretation. In most of the cases assessment $\bar{q}$ has been based on dates, reported as absolute values in completed weeks, and to a lesser extent based on clinical criteria.

\section{ANALYSIS OF DATA}

By preparing scattergrams it has been possible to identify probable errors. These were 
corrected when it was found to be due to a fault in recording, but nine that were unequivocally wrong were excluded. The data have been analysed to provide means and SDs, and using the LMS method of Cole, ${ }^{23}$ centile distributions for birth weights and head circumferences have been produced. This method assumes that data can be normalised by using a power transformation, thus removing any skewing from a distribution. The optimal power (L) to obtain normality has been calculated for each week of gestation, and the trend summarised by a smoothed (L) curve using the simplified least squares procedure described by Savitzky and Golay. ${ }^{4}$ Trends in the coefficient of variation (S) are also smoothed. Together with the curves for the mean (M), the resulting $L, M$, and $S$ values can be used to calculate any centile curve and convert measurements into exact SD scores.

If $x$ represents a particular birth weight, the SD score, $Z$, is calculated as:

$$
\frac{\mathrm{Z}=(\mathrm{x} / \mathrm{M})^{\mathrm{L}}-1}{\mathrm{LS}}
$$

The results are presented as graphs for the total babies of each sex separately. These total groups have also been analysed as subgroups (still separately for each sex) for twin 1 and twin 2 , and for mixed sex and same sex pairs. For convenience in showing comparisons on the same graphs, frequently the 'mean' value only is shown. These are usually very close to the median values not only for occipitofrontal circumferences but also for birth weights, which after birth rapidly acquire a skewed centile distribution.

\section{SINGLETON STANDARDS FOR COMPARISON}

The data from the National Scottish Birth Study (1975-89) have been chosen to provide comparative information of birth weights and head circumferences of singletons, being a recent study with very large numbers and

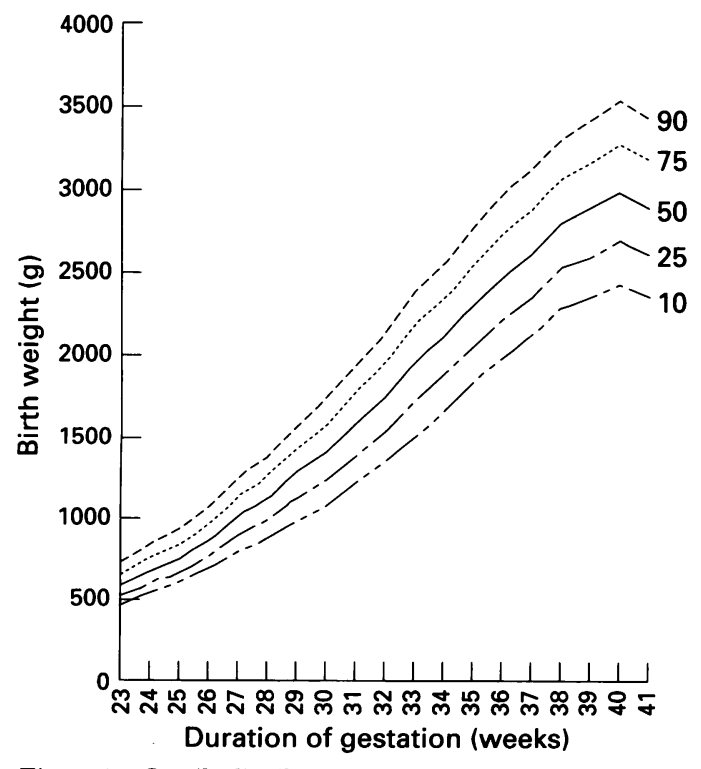

Figure 1 Centile distribution of birth weights of twin boys.

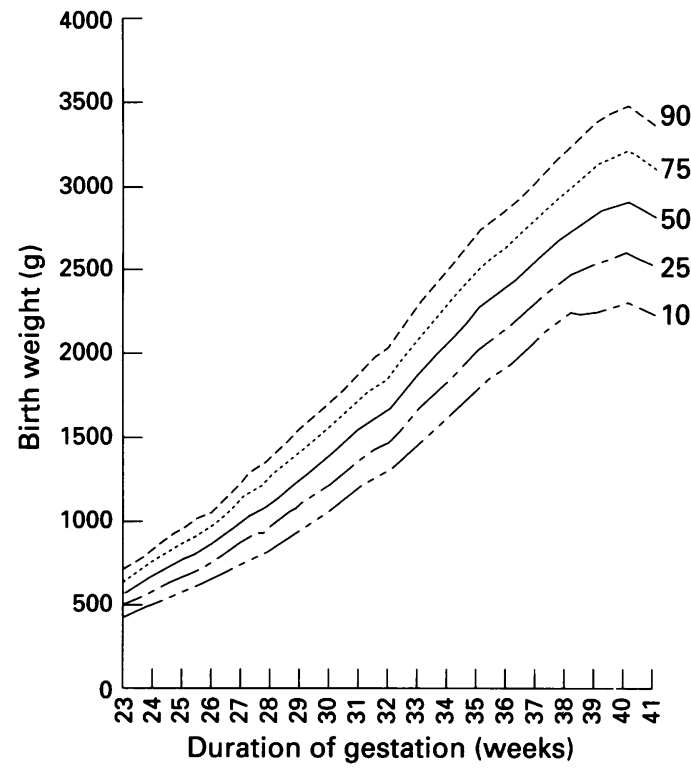

Figure 2 Centile distribution of birth weights of twin girls.

reasonably comparable geographically. ${ }^{1}$ Data of birth weights of 451510 boy and 425551 girl singletons and head circumferences of 259065 boy and 244093 girl singletons were used in that study.

ETHICAL APPROVAL

Formal ethical approval was not considered necessary by the chairman of the local research ethics committee in view of the anonymity of data collection.

\section{Results}

BIRTHWEIGHT CENTILES

Birthweight centiles for boys and girls are presented as graphs (figs 1 and 2). Mean birth weight values for the total group of boys are compared with the total group of girls in fig 3 . This confirms other reports that at all stages of gestation the fetuses of boys are bigger than girls, ${ }^{156}$ the difference being of the order of $50 \mathrm{~g}$ before 31 weeks and rising to around

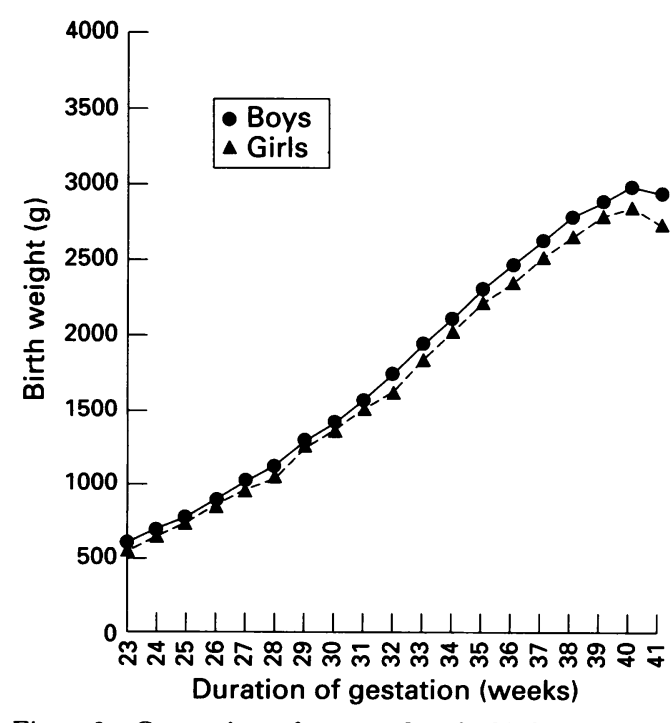

Figure 3 Comparison of mean values for birth weights of twin boys and girls. 

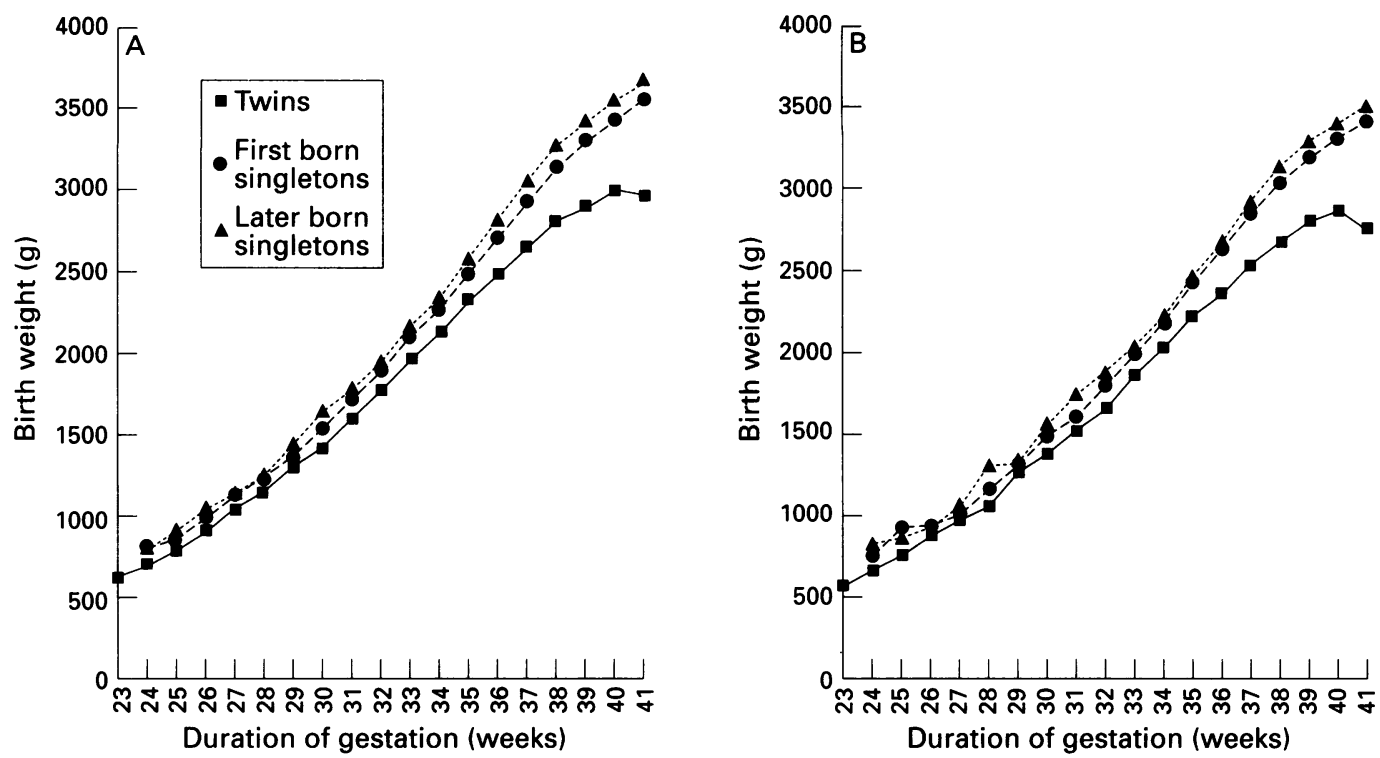

Figure 4 Comparison of the mean birth weights of twins and singletons: $(A)$ boys, $(B)$ girls.

$100 \mathrm{~g}$ as gestation progresses. Not surprisingly, this is similar to the differences found between newborn singleton boys and girls. ${ }^{1}$

The number of twins reported in the Scottish series was about 1000 less than the present series for each sex. ${ }^{1}$ The proportion born with longer gestation, however, was much greater in the Scottish figures than the English - about $25 \%$ of the Scottish twins were born with length of gestation of 39 weeks or longer - approximately double the proportion for the same gestational period for English twin births. Overall, the birthweight pattern is similar in the two series. However, below 32 weeks' gestation there is a suggestion that Scottish twin babies were fractionally heavier than the English, but only of the order of $50 \mathrm{~g}$ for median values, whereas for gestations over 34 weeks' duration the English twins tended to be the larger by a similar amount.

Comparisons of birthweight values for the first and second twins showed that for both sexes at most gestational periods the mean values for twin 1 are slightly heavier than twin 2 , but only by about $40-50 \mathrm{~g}$. Mean birth weights have also been compared in a similar way for those babies who were members of a same sex pair with those from mixed sex pairs. At most gestational ages the mean weight of twins of unlike sex are slightly higher than that of twins of the same sex, the difference being in the order of $50 \mathrm{~g}$. As all twins from mixed pairs are dizygotic and more than half of same sexed twins are monozygotic; this would fit in with reports that dizygotic twins are bigger than monozygotic at birth. ${ }^{6}$ The various factors that influence birth weight of twins have been discussed in depth by Campbell and Samphier in attempting to devise empirical birthweight standards for twins. ${ }^{8}$ They concluded that this was impossible because of the range and complexity of the factors involved, and anything other than gestation at delivery should be ignored as they contributed much less to the variations in birth weight.
Using the Scottish singleton data for comparison, twin birthweight data are compared with singletons in fig 4 for boys and girls. The singletons have been subdivided according to whether they are first born or later born, the mean values for the latter being consistently the greater. The figure demonstrates that singletons are bigger than twins from before 24 weeks' gestation, though the differences become more marked from 35 weeks onwards.

\section{OCCIPITOFRONTAL HEAD CIRCUMFERENCES}

Centiles are shown as graphs in figs 5 and 6 for boys and girls respectively. These values are about $5 \mathrm{~mm}$ greater for boys than girls throughout the later stages of gestation. Comparisons with the Scottish singleton standards are shown in fig 7, which demonstrate little difference up to 35 weeks' gestation, but a progressively increasing disparity after that.

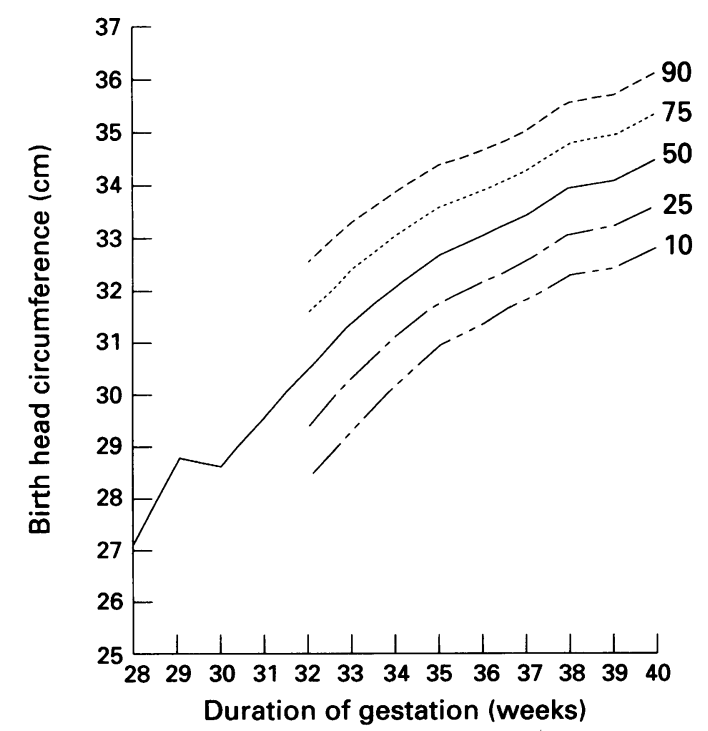

Figure 5 Centile distribution of head circumferences of twin boys. 


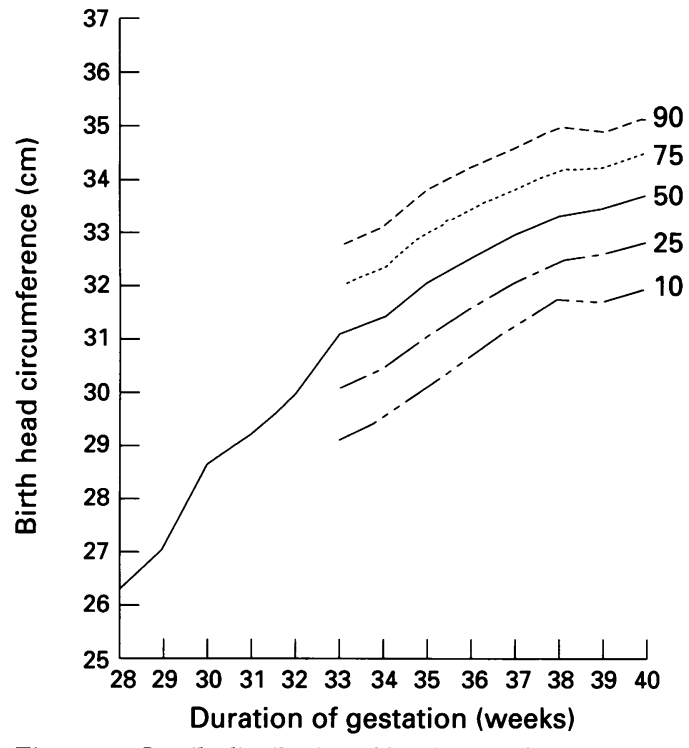

Figure 6 Centile distribution of head circumferences of twin girls.

\section{Discussion}

Twin birthweight values reported here accord well with the few available previous reports, most of which comprise only small numbers. ${ }^{5-7}$ 9-15 $\mathrm{By}$ far the biggest comparable study is that for Scotland, ${ }^{1}$ which provides data on birth weight, length, and head circumference for about 877000 singletons born between 1975 and 1989 and on birth weight for about 17000 twins.

Most of the previous publications listed have suggested that the fall off in the weight of twins compared with singletons does not become evident until a gestation of about 30 weeks. Indeed, comparison of the present data with those of the most widely used British standards (the Gairdner-Pearson (1985) ${ }^{16}$ and Tanner-Thomson (1970) charts ${ }^{17}{ }^{18}$ ) would imply this. Those singleton data were based, however, on relatively small numbers totalling about 15000 each of later born infants of both sexes with gestational ages distributed from 32 weeks onwards. Values for a lower age were derived from composite data of Babson et al (1970) for infants of 28 weeks old (sexes combined) and the curves drawn from these to join the others at 32 weeks ${ }^{19}$; this has resulted in great approximation. Another American source of singleton data often referred to is that of Lubchenko et al. ${ }^{20}$ The new Scottish data ${ }^{1}$ with very large numbers provides a much better standard for comparison (as well as avoiding possible effects of secular trends) and it is apparent from fig 4 that there is a difference in fetal size from a very early stage, though this becomes proportionately more evident from about 35 weeks' gestation onwards. The close similarity between the birthweight data of these twins and those of the Scottish data confirms that Scottish singleton standards may appropriately be used for comparison.

Singleton data show that first born babies are smaller than those from subsequent pregnancies, and the disparity in twin birth weights from singletons is therefore greater when including later pregnancies than when first born singletons only are considered. It has not been possible to subdivide twin birth data according to whether these pregnancies were first or subsequent, though a similar trend has been reported by Rydhström from Sweden, where twins born to multiparous women weighed an average of $250 \mathrm{~g}$ more than twins born to primiparous women. ${ }^{15}$

A sex difference in birth measurements is apparent from the earliest gestational ages at which data are available (as with singletons). From 32 weeks onwards boys on average are over $100 \mathrm{~g}$ heavier than girls (fig 3), ${ }^{112}$ and throughout the full gestational period their head circumference averages $5 \mathrm{~mm}$ greater than girls.

No data have been obtained in this report for birth lengths and little has been reported elsewhere. Birth length measurements are notoriously unreliable and, had the information been available, it would probably have been misleading, having been obtained from so
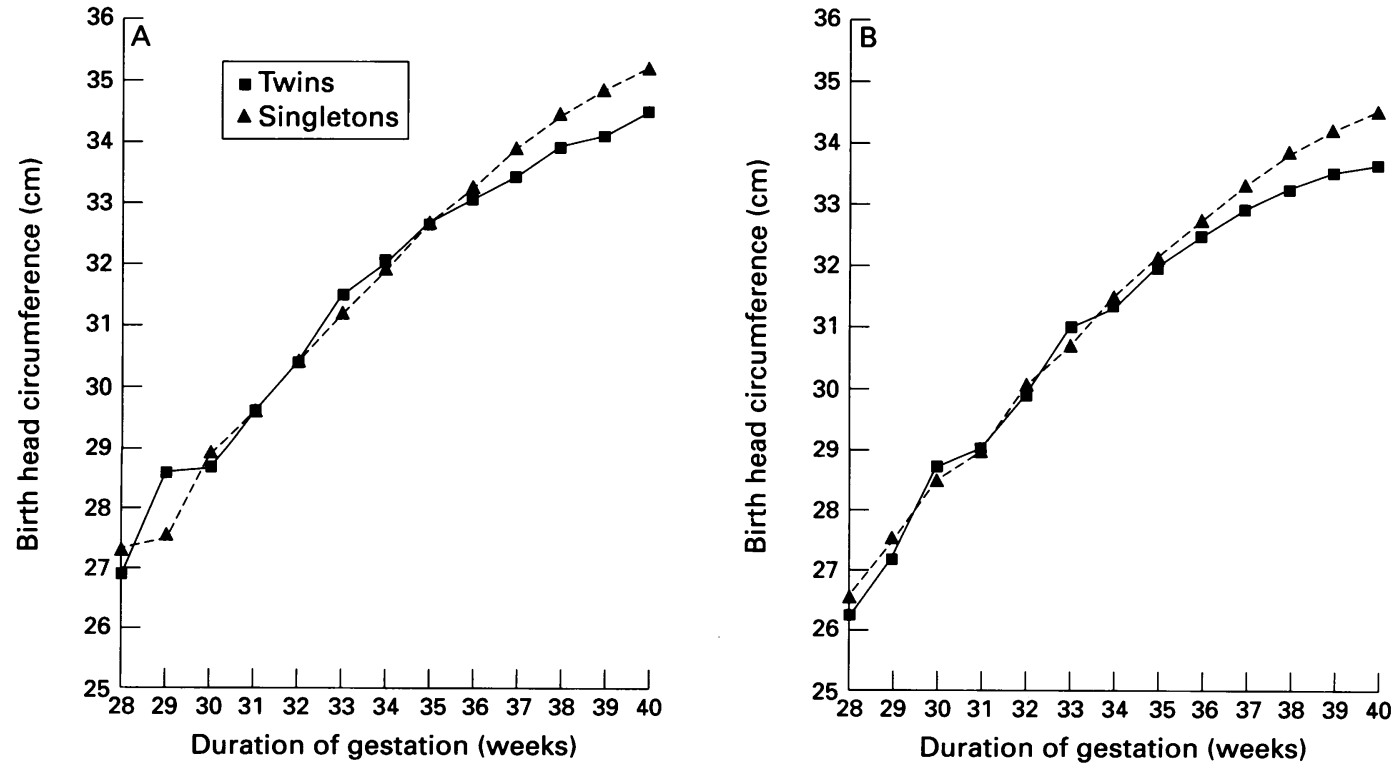

Figure 7 A comparison of the mean values for head circumference of singletons and twins: $(A)$ boys, (B) girls. 
many different centres with different reliability of measurement technique. Walli et al compared a small series of twins birth lengths with singletons without separation according to sex for the twins. ${ }^{21}$ They found the combined group lengths averaged about $1 \mathrm{~cm}$ less than singleton girls, or $2 \mathrm{~cm}$ less than singleton boys from 36 weeks' gestation (and possibly earlier, but the numbers were too small). Wilson had earlier made similar observations and also with head circumference measurements, ${ }^{12}$ which in the present study provide a clue into the pattern of bony growth. Head circumferences as shown in the standard British charts for preterm singletons (Gairdner-Pearson, 1985) have values that appear to be small when compared with the Scottish data and less than the current twin values. ${ }^{16}$ They were derived from composite data of Babson (1975) ${ }^{19}$ and may not be appropriate for present day British neonates.

When comparing the current twin head circumference values with the Scottish singleton ones, ${ }^{1}$ the implication is that head circumference, unlike weight, does not begin to fall off in twins until after 35 weeks' gestation.

It is interesting to speculate on the long term implications of the smaller size of twins, and whether this is likely to result in any disadvantage long term. Singletons who are 'light for dates' often grow poorly subsequently, ${ }^{22-27}$ but this appears to be more of a problem if their growth in length is similarly impaired at birth. Those underweight, but of a reasonable length (many of whom have presumably suffered from relatively short term undernutrition through placental insufficiency), mostly show reasonable catch up subsequently. More information about the birth lengths of twins compared with singletons might give a clue to understanding their subsequent growth.

A recent twin study evaluated heights and weights of twins through childhood. ${ }^{28}$ This showed that twins born with weight on or above the tenth centile, based on singleton standards for gestational age, grew as well or better in height than comparable singletons (as judged by the heights of their own siblings and parents). Those with birth weights between the 5 th and 10th singleton standards showed trivial degrees of impairment, whereas only those below the 5 th centile were at a permanent disadvantage. All groups of twins, however, were underweight compared with singletons throughout their growing years, implying that their lower birth weights may have had a more permanent effect on weight than on length. A similar observation had been made by Wilson through longitudinal observations on twins up to the age of 4 years. ${ }^{29}$

In view of these observations, which birthweight standards are the appropriate ones to use for twins? Are the implications of being 'light for gestational age' the same for twins as they are for singletons? Are the specific factors that cause twins to be smaller than singletons at birth unique to multiple pregnancies, and therefore different from those that otherwise cause babies to be inappropriately small? In answer to the last question we would suggest that they are, and they probably affect weight (and perhaps degrees of fatness) more than bony measurements. This results in a better long term height prognosis than for singletons of equivalent degrees of smallness, though leaving them with a permanent tendency to be of lesser weight (possibly due to lesser fat) that is probably not a disadvantage. Of course, twins will also be susceptible to all the other causes of being inappropriately light for gestational age that singletons experience, and when that is the case they will be subject to the same long term adverse implications for growth. To assess appropriateness of twins' birth weights, we would therefore recommend the use of these new standards. The criteria employed in determining the degree of inappropriateness of birth size, with all the long term implications, should be based on twin and not singleton standards.

We gratefully acknowledge the collaboration of representative of maternity and neonatal units at the 36 centres listed below who provided the data on which this paper is based. We express our appreciation and gratitude to the Medical Research Council, the Department of Health, and other grant giving bodies who funded research in some of the centres that made these data available, and also the many people involved in data collection over the years. We are grateful to Dr T J Cole and Mr P Singer for statistical help and advice and to the Scottish Health Service for permission to use data for comparison.

Participating centres: Basingstoke District Hospital; Participating centres: Basingstoke District Hospital; Birmingham Maternity Hospital; Blackpool: Victoria Hospital; Bradford: Royal Infirmary/St Luke's Hospital; Bristol: St Michael's Hospital; Chelmsford: St John's Hospital; Derby Gity General Hospital; Eastbourne District General Hospital; Grimsby Maternity Hospital; Guildford: The Royal Surrey County Hospital; Halifax General Hospital; Harrogate General Hospital; Hull Maternity Hospital; Keighley: Airedale General Hospital; Royal Lancaster Infirmary; Leeds: General Infirmary, St James's Hospital; Leicester Royal Infirmary; Royal Liverpool Chelsea Hospital, University College London Hospitals and Medical School; Manchester: St Mary's Hospital, Withington/Wythenshaw Hospitals; Newcastle: Northern Regional Maternity Survey Office; Northallerton: Friarage Regional Maternity Survey Office; Northallerton; Friarage Hospital; Nottingham: University Hospital, Queen's Medical Centre; Oxford: John Radcliffe Hospital; Peterborough District Hospital; Plymouth General Hospital; Scunthorpe General Hospital; Sheffield: Jessop Hospital for Women; Southampton: Princess Anne Hospital; Stoke on Trent: North Staffordshire Maternity Hospital; Stourbridge: Wordsley Hospital; Wakefield: Pinderfields General Hospital; York District Hospital.

Charts for the twin birth weights and head circumferences will be published by Castlemead Publications, 12 Little Mundells, Welwyn Garden City, Herts AL7 1EW.

1 Information and Statistics Division, Scottish Health Service Common Services Agency. Scotland birthweight, head circumference and length for gestational age. ISD circumference and

2 Cole TI. The British, American NCHS, and Dutch weight st. American standards compared using the LMS method.
fournal of Human Biology 1989; 1: 397-408.

3 Cole TJ. The LMS method for constructing normalised growth standards. Eur f Clin Nutr 1990; 44: 45-60.

4 Savitsky A, Golay MJE. Smoothing and differentiation of data by simplified least squares procedures. Anal Chem 1964; 36: 1627-39.

5 Asaka A, Imaizumi Y, Inouye E. Analysis of multiple births in Japan. 1. Weight at birth among 12392 pairs of twins. fpn f Hum Genet 1980; 25: 65-71.

6 Corey LA, Nance WE, Kang KW, Christian JC. Effects of type of placentation on birth weight and its variability in monozyotic and dizygotic twins. Acta Genet Med Gemellol monozygotic and dizygotic

7 Timlin D. The effect of zygosity on the birth weight of twins in Aberdeen and north east Scotland. Acta Genet Med in Aberdeen and north east Scotland 1979; 28: 353-60.

8 Campbell DM, Samphier M. Birthweight standards for twins. In: MacGillivray I, Campbell DM, Thompson B, eds. In: MacGillivray I, Campbell DM, Thompson B, eds. Twinning and twins. Chichester: John Wiley, 1988. multiple pregnancy in man. $\mathcal{F}$ Endocrinol 1952; 8: 386-401.

10 Karn $M$. Birth weight and length of gestation of twins, together with maternal age, parity

$11 \mathrm{Karn} \mathrm{M}$. Twin data: a further study of birthweight, gestation time, maternal age, order of birth and survival. Annals of Eugenics 1953; 17: 233-48. 
12 Wilson RS. Twins: measures of birth size at different gestational ages. Ann Hum Biol 1974; 1: 57-64.

13 Daw E, Walker J. Growth differences in twin pregnancy. Br f Clin Pract 1975; 29: 150-2.

14 MacGillivray I. In: MacGillivray I, Nylander PPS, Corney $\mathrm{G}$, eds. Human multiple reproduction. Philadelphia: WB Saunders, 1975 .

15 Rydhström $\mathrm{H}$. A birthweight-for-gestation standard based on 4737 twins born in Sweden between 1983 and 1985 . Acta Obstet Gynecol Scand 1992; 71: 506-11.

16 Gairdner-Pearson (1971). Growth and development record, boys and girls: preterm - 2 years, length/weight/head circumference. Ware: Castlemead Publications, 1983.

17 Tanner-Thomson (1970). Growth and development record, boys/girls: 32-42 weeks. Birth weight allowing for maternal boys/girls: 32-42 weeks. Birth weight allowing for mater

18 Thomson AM, Billewicz WZ, Hytten FE. The assessment of fetal growth. Fournal of Obstetrics and Gynaecology of the British Commonvealth 1968; 75, 903-16.

19 Babson SG, Behrman RE, Lessel R. Fetal growth: liveborn birth weights for gestational age of white middle clas infants. Pediatrics 1970; 45: 937-44.

20 Lubchenko LO, Hansman C, Dressler M, Boyd E. Intrauterine growth as estimated from live-born birth weight data at 24-42 weeks gestation. Pediatrics 1963; 32: 793-800.

\section{Appendix}

Table of values used to calculate birthweight centiles for boys

\begin{tabular}{|c|c|c|c|c|c|}
\hline $\begin{array}{l}\text { Gestation } \\
\text { (weeks) }\end{array}$ & $L$ & $\begin{array}{l}L \\
\text { (smoothed) }\end{array}$ & $S$ & $\begin{array}{l}S \\
\text { (smoothed) }\end{array}$ & Mean \\
\hline 23 & -2.96 & 0.00 & 0.13 & $0 \cdot 17$ & 583 \\
\hline 24 & -1.07 & 0.00 & 0.15 & $0 \cdot 17$ & 675 \\
\hline 25 & -0.68 & 0.00 & $0 \cdot 17$ & $0 \cdot 17$ & 752 \\
\hline 26 & -0.8 & 0.00 & 0.17 & $0 \cdot 17$ & 864 \\
\hline 27 & 0.99 & 0.39 & $0 \cdot 16$ & $0 \cdot 18$ & 1016 \\
\hline 28 & 0.92 & 0.84 & $0 \cdot 19$ & $0 \cdot 17$ & 1127 \\
\hline 29 & 0.89 & $1 \cdot 19$ & $0 \cdot 19$ & $0 \cdot 18$ & 1289 \\
\hline 30 & $1 \cdot 15$ & 1.02 & $0 \cdot 16$ & $0 \cdot 18$ & 1414 \\
\hline 31 & $1 \cdot 19$ & $1 \cdot 13$ & 0.18 & $0 \cdot 18$ & 1588 \\
\hline 32 & 0.94 & $1 \cdot 21$ & $0 \cdot 19$ & $0 \cdot 17$ & 1752 \\
\hline 33 & 1.42 & $1 \cdot 16$ & $0 \cdot 16$ & $0 \cdot 17$ & 1957 \\
\hline 4 & $1 \cdot 10$ & $1 \cdot 11$ & $0 \cdot 16$ & $0 \cdot 16$ & 2118 \\
\hline 35 & 0.88 & 0.96 & $0 \cdot 16$ & $0 \cdot 16$ & 2311 \\
\hline 36 & 0.91 & 0.85 & $0 \cdot 16$ & $0 \cdot 16$ & 2475 \\
\hline & 0.68 & 0.92 & $0 \cdot 15$ & $0 \cdot 15$ & 2625 \\
\hline 38 & $1 \cdot 27$ & $1 \cdot 15$ & $0 \cdot 14$ & $0 \cdot 14$ & 2809 \\
\hline & 1.07 & $1 \cdot 10$ & $0 \cdot 14$ & $0 \cdot 14$ & 2895 \\
\hline 40 & 1.06 & $1 \cdot 10$ & $0 \cdot 14$ & $0 \cdot 14$ & 299 \\
\hline 71 & -0.36 & $1 \cdot 10$ & 0.16 & 0.14 & 2907 \\
\hline & $-1 \cdot 29$ & $1 \cdot 10$ & $0 \cdot 13$ & $0 \cdot 14$ & 2694 \\
\hline
\end{tabular}

$L=$ optimal power; $S=$ coefficient of variation.

Table of values used to calculate birthweight centiles for girls

\begin{tabular}{|c|c|c|c|c|c|}
\hline $\begin{array}{l}\text { Gestation } \\
\text { (weeks) }\end{array}$ & $L$ & $\begin{array}{l}L \\
\text { (smoothed) }\end{array}$ & $S$ & $\begin{array}{l}S \\
\text { (smoothed) }\end{array}$ & Mean \\
\hline 23 & $-2 \cdot 12$ & 1.00 & 0.08 & $0 \cdot 19$ & 547 \\
\hline 24 & 0.98 & 1.00 & 0.14 & $0 \cdot 19$ & 643 \\
\hline 25 & 1.52 & 1.00 & $0 \cdot 17$ & $0 \cdot 19$ & 745 \\
\hline 26 & -0.52 & 1.00 & 0.18 & $0 \cdot 19$ & 836 \\
\hline 27 & $1 \cdot 11$ & 0.86 & 0.21 & 0.2 & 969 \\
\hline 28 & 1.46 & 0.99 & 0.22 & $0 \cdot \overline{2}$ & 1051 \\
\hline 29 & 1.34 & 1.46 & $0 \cdot 19$ & $0 \cdot 19$ & 1256 \\
\hline 30 & 1.02 & $1 \cdot 26$ & $0 \cdot 18$ & $0 \cdot 18$ & 1368 \\
\hline 31 & 1.34 & $1 \cdot 14$ & 0.16 & $0 \cdot 17$ & 1524 \\
\hline 32 & 1.05 & 1.09 & $0 \cdot 17$ & $0 \cdot 17$ & 1642 \\
\hline 33 & 1.05 & 1.09 & $0 \cdot 18$ & $0 \cdot 17$ & 1852 \\
\hline 34 & 1.03 & 1.07 & $0 \cdot 17$ & $0 \cdot 17$ & 2029 \\
\hline 35 & $1 \cdot 11$ & 1.04 & $0 \cdot 15$ & $0 \cdot 16$ & 2229 \\
\hline 36 & $1 \cdot 14$ & 1.06 & $0 \cdot 16$ & 0.15 & 2360 \\
\hline 37 & 0.81 & 1.03 & $0 \cdot 15$ & 0.15 & 2527 \\
\hline 38 & 1.22 & 0.98 & $0 \cdot 14$ & $0 \cdot 14$ & 2679 \\
\hline 39 & 0.90 & 1.45 & 0.14 & 0.16 & 2800 \\
\hline 40 & 1.06 & 1.45 & $0 \cdot 15$ & $0 \cdot 16$ & 2867 \\
\hline 41 & $1 \cdot 26$ & 1.45 & $0 \cdot 20$ & $0 \cdot 16$ & 2766 \\
\hline 42 & $-3 \cdot 28$ & 1.45 & 0.11 & $0 \cdot 16$ & 3807 \\
\hline
\end{tabular}

$\mathbf{L}=$ optimal power; $S=$ coefficient of variation.
21 Walli R, Stettler T, Largo RH, Fanconi A, Prader A. Gewicht, Länge und kopfumfang neugeborener kinder und ihre Abhäugigkeet von mürterlechen un kindlichen faktoren. Helvetica Paeditrica Acta 1980; 35: 397-418.

22 Babson SG. Growth of low birth weight infants. f Pediatr 1970; 77: 11-8.

23 Fitzhardinge PM, Steven EM. The small-for-dates infant and later growth patterns. Pediatrics 1972; 49: 671.

24 Chamberlain RN, Simpson RH. Cross sectional studies on physical growth in twins, postmature and small for dates children. Acta Paediatr Scand 1977; 66: 457-63.

25 Lubchenko LO. The high risk infant. Philadelphia: WB Saunders, 1976.

26 Westwood M, Kramer MS, Munz D, Lovett JM, Watters GV. Growth and development of full term nonasphyxiated small-for-gestational age newborns: follow up through adolescence. Pediatrics 1983; 71: 376-82.

27 Paz I, Seidman DS, Danon YL, Laor AL, Stevenson DK, Gale R. Are children born small for gestational age at increased risk of short stature? Am f Dis Child 1993; 147: 337-9.

28 Buckler JMH, Buckler JB. Growth characteristics in twins and higher order births. Acta Genet Med Gemellol (Roma) 1987; 36: 197-208.

29 Wilson RS. Growth standards for twins from birth to four years. Ann Hum Biol 1974; 1: 175-88.

Table of values used to calculate birth head circumference centiles for boys

\begin{tabular}{|c|c|c|c|c|c|}
\hline $\begin{array}{l}\text { Gestation } \\
\text { (weeks) }\end{array}$ & $L$ & $\begin{array}{l}L \\
\text { (smoothed) }\end{array}$ & $S$ & $\begin{array}{l}S \\
\text { (smoothed) }\end{array}$ & Mean \\
\hline 28 & $5 \cdot 90$ & $0 \cdot 81$ & 0.06 & 0.06 & $27 \cdot 1$ \\
\hline 29 & 4.97 & 0.81 & 0.06 & 0.06 & $28 \cdot 8$ \\
\hline 30 & 0.09 & $0 \cdot 81$ & 0.06 & 0.06 & $28 \cdot 6$ \\
\hline 31 & $0 \cdot 16$ & 0.81 & 0.06 & 0.06 & $29 \cdot 6$ \\
\hline 32 & $3 \cdot 34$ & 0.98 & 0.05 & 0.05 & 30.5 \\
\hline 33 & $-0 \cdot 17$ & $2 \cdot 24$ & 0.05 & 0.05 & $31 \cdot 4$ \\
\hline 34 & $3 \cdot 64$ & 1.98 & 0.04 & 0.04 & $32 \cdot 1$ \\
\hline 35 & 1.96 & 1.41 & 0.04 & 0.04 & $32 \cdot 7$ \\
\hline 36 & -0.05 & 1.83 & 0.04 & 0.04 & $33 \cdot 1$ \\
\hline 37 & $2 \cdot 07$ & 1.31 & 0.04 & 0.04 & 33.5 \\
\hline 38 & $2 \cdot 35$ & $1 \cdot 31$ & 0.04 & 0.04 & 34.0 \\
\hline 39 & $1 \cdot 82$ & 1.31 & 0.04 & 0.04 & $34 \cdot 1$ \\
\hline 40 & $2 \cdot 39$ & 1.31 & 0.04 & 0.04 & 34.5 \\
\hline
\end{tabular}

$\mathrm{L}=$ optimal power; $\mathrm{S}=$ coefficient of variation.

Table of values used to calculate birth head circumference centiles for girls

\begin{tabular}{lrllll}
\hline $\begin{array}{l}\text { Gestation } \\
\text { (weeks) }\end{array}$ & $L$ & $\begin{array}{l}L \\
\text { (smoothed) }\end{array}$ & $S$ & $\begin{array}{l}S \\
\text { (smoothed) }\end{array}$ & Mean \\
\hline 28 & 1.37 & 1.35 & 0.07 & 0.05 & 26.3 \\
29 & -3.79 & 1.35 & 0.05 & 0.05 & 27.1 \\
30 & -1.80 & 1.35 & 0.05 & 0.05 & 28.6 \\
31 & 5.30 & 1.35 & 0.05 & 0.05 & 29.2 \\
32 & 1.92 & 3.42 & 0.04 & 0.05 & 29.9 \\
33 & 3.65 & 3.80 & 0.05 & 0.05 & 31.1 \\
34 & 3.07 & 3.01 & 0.05 & 0.04 & 31.4 \\
35 & 3.34 & 3.04 & 0.04 & 0.05 & 32.1 \\
36 & 2.58 & 2.90 & 0.04 & 0.04 & 32.5 \\
37 & 1.58 & 1.77 & 0.04 & 0.04 & 33.0 \\
38 & 2.63 & 1.77 & 0.04 & 0.04 & 33.3 \\
39 & -1.77 & 1.77 & 0.04 & 0.04 & 33.5 \\
40 & 1.80 & 1.77 & 0.04 & 0.04 & 33.7 \\
\hline
\end{tabular}

$\mathrm{L}=$ optimal power; $\mathrm{S}=$ coefficient of variation. 